\title{
A New Age of Discovery: The Post-GIS Era
}

\author{
Francis HARVEY \\ University of Minnesota·fharvey@umn.edu
}

This contribution was double-blind reviewed as extended abstract.

\begin{abstract}
GIS has been successful beyond measure around the world. Following Donald Norman, successful technologies disappear; they become infrastructure. Now almost 50 years after its inception and successful disappearance to become an integral foundation for life in the information age, it's time to think of issues in the Post-GIS era. This presentation specifically considers how the growing ubiquity of computing infrastructures around the world open potentials for a new era of discovery in global science and geographic information technologies. Because of the shifts in access and abilities to use digital information, the potential of geographic information is bursting the limits of GIS, which originated at the end of industrial era and still reflects those origins. Research challenges abound. Post-GIS science and technologies hold key importance in facilitating connections between the physical and virtual worlds, melding them into productive arrangements and raising important questions about changing social and cultural arrangements. Regarding science, networked digital infrastructures hold the potential to alter research in fundamental ways. Known as the Fourth Paradigm of science, data intensive science goes hand-in-hand with intensely collaborative large group research that considers location in fascinating new ways. Recent scientific activities show how changes in the geographical organization of our work and conduct of science have already begun to take place. The presentation closes with considerations of central issues for this new age and recent activities that highlight the importance of educating future professionals and scientists for the post-GIS era.
\end{abstract}

\section{The Future Is Already Here, It's just Unevenly Distributed}

Connecting to several ongoing discussions and contributions from colleagues, this paper and related presentation at GI_Forum and AGIT 2013 suggest that the future of GIS will be a post-GIS era of discovery building on the increasing ubiquity of computing infrastructures. Already we know the world is changing but the variability and scope are daunting, even overwhelming. Yet, for most of us the future is already there in some shape or form. After centuries of looking beyond the horizon for new discoveries, with growing abilities through ubiquitous computing, people are realizing that discoveries may be made in the distance and in the unknown, but discoveries can also be made among the many unknowns and lesser knowns, both near and far. Computer networks, ubiquitous computing, and the internet of things are the foundation for a new era of discovery involving location technologies. Today, anyone can make a map or orientate themselves with location technologies, starting with the over one billion (October 2011) people who have downloaded

Jekel, T., Car, A., Strobl, J. \& Griesebner, G. (Eds.) (2013): GI_Forum 2013. Creating the GISociety. (C) Herbert Wichmann Verlag, VDE VERLAG GMBH, Berlin/Offenbach. ISBN 978-3-87907-532-4.

(C) ÖAW Verlag, Wien. eISBN 978-3-7001-7438-7, doi:10.1553/giscience2013s272. 
Google Earth, the millions of Bing!, Yahoo!, World Wind users, the 6 billion mobile phone subscribers (WORLD BANK 2012), and the millions of GIS users. When location-based computational approaches become accessible to the majority of the earth's inhabitants, human society, planet-wide, has moved on from the GIS era. Yet, the cup is not really half full, it is really, at this point, half empty. Although GIS has had an impact comparable to the microscope on the world (ABLER 1991), many have potential location-based systems capacity through simple text messages and cell tower triangulation already allow unparalleled access to location technology compared to abilities just twenty years ago. While people may not all be able to make maps, and those who can are not always thinking of making maps, all people with access to mobile phones certainly can use location technologies.

The key difference from past eras, is that with location technologies, the new era of discovery is the discovery of the previously unknown, or unknown unknowns, if you prefer. It may finding the history of a neighborhood that reveals the presence of a hazardous waste site long forgotten, the discovery of animal migration, the discovery of how underrepresented groups utilize public transportation, or maybe the discovery of one of the world's most beautiful castles. Further, it will be different then all past eras of discovery, because at no other time in human history have the capabilities of information technologies ever been so readily available to the majority of people. And GI technologies are central to this era. We see that already in volunteered geographic information (VGI), projects in which citizen cartographers volunteer their time and knowledge to contribute geographic information to countless civic projects (GOODCHILD 2007). The internet has and still is transforming the way maps are made and people share geographic information. Some projects are global in scope; some are local. All involve a good measure of discovery, the fascination with learning and knowing what was previously unknown. Many of these projects also follow concepts of citizen science (HAKLAY et al. 2008). Drawing on these possibilities, other scientists are developing approaches to use these data sources to make our cities 'smarter' and reduce traffic congestion, address environmental issues, and improve the quality of life for now and the future (ROCHE et al. 2012). Scientists are also drawing on concepts of large data sources to develop computerized approaches to augment existing technologies and arrangements (WALCOTT-BRYAN et al. 2012).

As with all eras, not all developments are always seen from a positive light. We should also think about where we tread. As with any wide-spread innovation, e.g. Telephones, television, cameras, automobiles, the developments and negotiations of new technologies are an involved process that engages multiple groups in society. Dystopian perspectives become vehicles for channeling concerns and anxieties. Countering fear-mongering means speaking to concerns about the use of surveillance technologies (ELWOOD \& LESZCZYNSKI 2011) and potentials for merging data sets to circumvent anonymity (HARVEY in press) among the many issues that raise concerns. The range of uses and concerns points to in importance of treating maps as opinion pieces (BROTTON 2012) and the already apparent use of location technology to provide ubiquitous orientation and ubiquitous surveillance. What GIS has begun to make possible, is already changing the world. We will, and we have in some cases, experienced the coordination of physical space with digital space (KURGAN 2013). Indeed, as William Gibson suggests, the future is already here, it's just unevenly distributed (GIBSON 2012). 


\section{Post-GIS Era: Beyond what We Know We Know}

The future maybe unevenly distributed, but much is of the present is also unknown, so what we think is possible may already be reality. Our realities will be different and beyond what we know we know. Our use of location technologies will continue to rely on cartographic representation and human facilities of interpretation (FABRIKANT 2012). But we should also think of the unknown unknown, the so-called black swan case in thinking about what discovery can mean beyond the internet and web, past the consumer orientation of most online activities, beyond the geoweb, far beyond the way the world is and was, and even beyond ourselves. There are many examples for the ways that our contemporaries reach beyond what we find and point to potentials. Unrelated to location technologies, but one of the more practical sites to find exciting hybridization of current technologies is the Ikea Hackers site (ikeahackers.net). Thousands of examples show how to hybridize and extend off-the-shelf Ikea products to fit new demands. One of the most provocative examples to recently appear is the hacked children's bicycle, Draisienne, made from two Frosta stools with pliers, a drill, a metal saw, and a 3D printer by Samuel Bernier and Andreas Bhend in Paris over 2.5 days (http://www.coroflot.com/samuelbernier/Hack-of-IKEAs-Frostastool).And even though geographers are quite a conservative group over-all when it comes to creative hacking of mapping technologies, thousands of examples from compatriots point to ways that mapping and maps can be hacked. From Rebecca Solnit's Infinite City (SOLNIT 2010) to the Atlas of Radical Cartography (MOGEL \& BHAGAT 2007) and many more, we can see how NeoGeography is a milestone in the shifting role of location technologies, but much more can and should be expected as information technologies become ubiquitous.

But before jumping in feet first to consider post-GIS futures let's though consider what do we know? When looking to the future, we still need to reflect on what we know and think about past successes and past limits. Considering GIS, any history, for example recent work by Dan Sui, Helen Couclelis, Dawn Wright, and others (Wright 2012, SuI 2012, COUCLELIS 2012) that points out numerous limits in GIS technology demonstrates an information processing architecture concept for working with location information moving with astonishing successes from the industrial production of map series by national mapping organizations (CHRISMAN 2006) to a completely altered world in which geospatial is potentially a part of every thing. GIS was part of a big shift in the information age moving from resolving technical aspects to the enablement of critical spatial thinking. And that is without a guarantee of success: many users of satellite navigation systems who fail to update their databases become aware of this only through bad experience (BROWN et al. 2012, BROWN et al. 2010) alone and unfortunately not too few accidents.

Some of the changes of the post-GIS era are definitely afoot: Google Earth is many times more widely used then even the most successful GIS. The ubiquity of sensors and devices with computational capabilities and connectivity to make sense of geographic relationships have supported in the first phase of innovation a raft of innovative location-based applications. The deluge of smartphone app points to the abilities of creative programmers to develop means for us to turn physical location and virtual connections and access into usually exciting and innovative means of discovery, but at times unsettling and even outright disturbing services. Which changes will become the basis for new rounds of innovative applications remains to be seen. We though should steel ourselves to the deep- 
reaching changes that are certain to continue. Already, $40 \%$ of the companies in the Fortune 500 in 2000 were no longer there in 2010 (SolIs 2012). We should expect similar changes to government and private actors in the GIS field.

Given the wide-reaching nature of these changes also we should remind ourselves that none of us holds a compass to guide us into the futures. We need to be ready for changes and discoveries not only in applications, but in the underlying technology itself. Perhaps one of the most significant changes that we will see in the next years is the resolution of GPS limits on indoor use and challenging environments by the complementary use of timing and inertial measurement units, such as recently revealed by DARPA, that in the space of 10 cubic millimeters holds three gyroscopes, three accelerometers, and a master clock (http://spacewatchtower.blogspot.com/2013/04/when-gps-fails-darpa-navigation-chip.html). Without a reliable compass, we need to think about discovery as a time for exciting innovations but also for disruptive activities.

\section{GIS Is Dead, Long Live GIS!}

One thing that may frighten many is the growing perspective that GIS is in its coffin awaiting burial, or at least on its death bed. Of course, not in Marc Antony's sense, when he says in Shakespeare's play Julius Caesar, "I come to bury Caeser, not to praise him", but in the sense of technological innovation cycles, in having run its course and now being one of many technologies, often indecipherable in detail from other types of technology and increasingly categorized to fit specific purposes (STAR 1999, BOWKER 2007, CHRISMAN 2007). Following on Don Norman's work, we should not mourn nor worry, but instead celebrate the many, some might say, countless positive impacts of GIS technology as it becomes part of everyday activities, disappearing effectively from concern (NORMAN 1993).

The millions of GIS deployments, used daily, transcend definitions of technology, as each instance involves a range of adaptations to assure it functions well with other technologies, people, and institutions. We see that in the closely related development of spatial data infrastructures SDI from centralized strategies to create and support inter-departmental data sharing to become distributed and service-orientated approaches (HARVEY et al. 2012). Or as Ed Parsons recently expressed, GIS is going from being a technology for applications, to becoming part of ubiquitous computing with "a bit of geospatial in everything."

In the post-GIS era, GIS is becoming part of the infrastructure. What does that mean? HENDRIKS, DESSERS AND VAN HOOTEGEM (2012) address the ambiguity of the term using a system-theoretical approach and pointing to the need to enhance considerations of the role of people in SDI. Nedovic-Budic, Harvey, de Man, Miscione and others have addressed similar impulses and draw on concepts and theories from science and technology studies and information studies to guide empirical studies and develop insights into the roles of people. Work by S. L. Star and G. Bowker that analyzes the concept of infrastructure (BOWKER 2007, STAR 1999, STAR \& RUHLEDER 1996) highlights the importance of considering multiple human and nonhuman dimensions of infrastructure as the foundation for change in the information age. 


\section{Science and much more Changing}

We have become used to the notion that immeasurable amounts of data are collected every day, almost constantly on the environment and about people. Sensors are everywhere. Abilities to access and use this information are fundamentally altering science. Considering the growing ubiquity of computational devices (BELL \& GRAY 1997), Jim Gray considers the changing roles and activities of science in data-intensive computing. It is a broad concept of computing for developing and refining theories in science and support the whole research cycle. Data exploration science, or eScience, consists of three primary activities: capture, curation, and analysis. Following Gray, this fourth paradigm, is must consider the broad range of data scientists, engineers, and experts involved in the successful management of digital data. Beyond the critical attention given infrastructure aspects, the shift to the fourth paradigm is what indeed critically distinguishes the post-GIS era from the GIS era. In considering the development of computational capabilities more broadly, Gray describe the previous third paradigm as the era dominated by computational approaches focused on simulating complex phenomena. Global change modeling, regional flood forecasting, scenario building, etc are some of the rich examples with many connections to GIS with countless examples that show the innovative scientific work done with GIS. With the growing amounts of data we now have available the shift to the fourth paradigm is taking place of necessity. Science is changing. The theoretical models grow too complicated to solve analytically and people started using simulations. Simulations generate a lot of data and now most scientists are no longer observing the world, but "looking" through data-based simulations that present information on their computers (MACEACHREN et al. 2005, MACEACHREN 1995). Computation ecology, medicine, biology, etc all represent vibrant fields that apply computer science techniques and technologies (WING 2006).

With all the data being created today, 2.5 quintillion bytes every day (http://www01.ibm.com/software/data/bigdata/), we are in need for information management and sustainable organization of infrastructures capable of supporting data-intensive computing. Standardized formats for data interchange such as the Hierarchical Data Format (HDF) and support for distributed processing through SpatialHadoop, help deal with the challenges. Fundamentally however, institutions are changing and adapting the technology to fit their circumstances and established management cultures. As Gray points out, we can see this occurring in scholarly publishing which is moving to greater open access of articles and also data (AHLQVIST et al. 2011).

For post-GIS technologies to support these changes in science, GIS, conceived of in an era dominated by the industrial age production of paper maps, and since evolved to support complex analytics and simulations, would need to evolve beyond its existing infrastructural organization. While in a transition still (SUI 2012) with much changing, it seems GIS has become an integral component of government and private institutions. Yet, it seems that the new ways to handle geographic information, signaled in the concept of NeoGeography (TURNER 2006), are already pointing to post-GIS technological and institutional architectures. 


\section{The Post-GIS Era in the Age of Ubiquitous Computing}

Considering the next-generation of geographic information technologies, several characteristics of the technologies and institutions will mark successful developments in the age of ubiquitous computing and data-intensive science. This paper points to several key aspects arising in the increasing abilities to merge interactions in the digital and physical worlds and strategies to create sustainable social coordination strategies.

A key aspect of the changes is the potential to create dynamic connectivity in multiple dimensions. Discoveries of the unknown knowns and unknown unknowns benefit from networked information technology to transcend physical space. We are no longer bound by spatial proximity to engage rich information with groups of people, nor by industrial age modes of information publishing. Widely used social networking applications make it already possible to connect to multiple interaction spaces simultaneously and, limited it seems largely only by our abilities to multi-task, to engage with people far beyond the scope of our immediate physical environment. This aspect is directly connected to increasing network capacity for smoothing the illusive divide between what we know of the world and what is. As the physical and virtual worlds of computing increasingly merge through discoveries, new potentials, relationships, and new vulnerabilities arise in the networked digital infrastructures that increasingly define what we know about the world around us. Finally, as Jim Gray points out and Mike Goodchild and others (GouLD et al. 2008) consider, the increasing amounts of data lead to intensively collaborative large group research. Indeed, social coordination from the individual, institutional, and international level seem more and more key foundations for science and government activities.

\section{Education: A Critical Component}

The development of these discoveries will of course not come by themselves. Many will come through commercial applications and services, but not alone. Teaching remains the key vehicle to develop intellectual capabilities. Yet, the changes, as we note in higher education around the world alone in the recent proliferation of Massive Open Online Courses (MOOCs) are themselves evolving as people explore abilities to use abilities of ubiquitous computing to learn to teach and teach to learn in different ways, which are not without detractors and concerns, but still seem poised to point to new modes of education delivery that could change many aspects of the educational systems developed in the industrial era.

Post-GIS era changes are already taking hold in education. Rob Edsall in a recent presentation [AAG meeting 2013] connects Jim Gray's fourth paradigm to crowd-sourcing of data and gamification showing not only the great potential for engaging students, but turning learning into a wider reaching pedagogy that starts and continues discoveries, also beyond education itself and helping define different ways to grasp relationships to others and place. This concept is reflected on the development of spatial citizenship (GRYL \& JEKEL 2012). While the approaches address issues in helping students learn to use GIS at one level, the more important aspect is going beyond technical interests and related instrumental knowledge. In this manner, this concept also provides a robust didactical framework for helping tomorrow's knowledge workers come to grips with the evolving 
technological landscape and develop the critical thinking capacities to support later contributions to their fields and help give meaning to their lives.

The spatial dimensions of space have been the focus of these engagements and offer a critical foundation for considering the fundamentals, principles, and concepts of post-GIS, including key activities of GeoCoding, issues of accuracy, and the central role of coding in these technologies. And because of the central roles of spatial analysis and cartographic visualization remain, teaching of fundamental principles provides keys to the possibilities of the future.

\section{$7 \quad$ The Post-GIS Age of Discovery}

The ubiquity of computing infrastructures around the world open potentials for a new era of discovery in global science and geographic information technologies. The changes that Jim Gray and others point to and this paper summarizes in terms of a vision for a post-GIS era are coming. How they will call and what they mean specifically are important issues for us to consider now before it is too late. We may already have heard of the idea of the "preemptive governing" idea coming from well-intentioned professionals at the forefront of the ubiquitous computing (HOWARD 2013) and other approaches to utilize ubiquitous computing data-intensive science to help create a better world. To develop, or in some cases, even reflect on the potentials, we need well educated scientists who can ground their decisions in a far-reaching responsibility.

In this sense the four key characteristics of post-GIS offer us starting points to consider central issues in research and teaching. In summary, the four characteristics are:

- Connectivity in multiple dimensions

- Increasing merging of physical and virtual worlds

- Networked digital infrastructures for people and things

- Intensively collaborative large group research in science and similar developments in industry and government

In the age of ubiquitous computing, the increasing merging of digital and physical worlds, location technologies are beginning to be augmented, altered, or even replaced. Distributed programming, which is already possible using Amazon's Mechanical Turk, device programming, data programming, democratized computing, and dangerous computing (DUMBILL 2013) will become key domains in which location technology specialists can have lasting impact.

With these changes research and teaching challenges abound, but have and will vary. At universities we have already begun laying the foundation for these changes (FISHER 2012, HARVEY et al. 2013). We see in these projects too that the future is already here, but also in the university it's still unevenly distributed. The post-GIS era may be part of that change. 


\section{Acknowledgements}

Many people have shared in discussions and considerations of issues that influenced the preparation of this paper. I wish to thank Dan Sui, Michael Goodchild, Werner Kuhn, Nadine Schuurman, Adam Iwaniak, Serena Coetzee, Antony Cooper, and Dawn Wright particularly. I also want to thank colleagues from the University of Minnesota's U-Spatial project for their contributions to lay the foundation for spatial research in tomorrow's universities. Of course, any errors or distortions in this paper remain my responsibility alone.

\section{Bibliography}

ABLER, R. F. (1991), Something old, something new. GIS, Geography, and the Social Sciences. Proceedings from NCGIA conference on GIS in the Social Sciences, Toronto.

Ahlqvist, O., Harvey, F., Ban, H., Chen, W., Fontanella, S., Guo, M. \& Singh, N. (2011), Making journal articles 'live': turning academic writing into scientific dialog. GeoJournal. doi:10.1007/s10708-011-9431-9.

Bell, G. \& Gray, J. (1997), The Revolution Yet to Happen. In: Denning, P. J. \& Metcalfe, R. H. (Eds.), Beyond Calculation: The Next Fifty Years of Computing. New York, Springer, 5-32.

BowkeR, G. (2007), Review: Memory practices in the sciences. RECIIS, 1 (2), 275-277. http://www.revista.icict.fiocruz.br/index.php/reciis/article/viewArticle/95.

Brotton, J. (2012), A history of the world in twelve maps. Penguin UK.

Brown, M., HARDING, J. \& Sharples, S. (2010), Exploring the Usability of Geographic Information: A Grounded Theory Analysis.

Brown, M., Sharples, S., Harding, J., Parker, C. J., Bearman, N., Maguire, M., JACKSON, M. (2012), Usability of Geographic Information: Current challenges and future directions. Applied ergonomics. http://www.sciencedirect.com/science/article/pii/S0003687012001718.

Chrisman, N. (2006), Charting the Unkown. How Computer Mapping at Harvard Became GIS. Redlands, CA, ESRI Press.

Couclelis, H. (2012), Climbing on a milestone for a better view: Goodchild's 'Geographical Information Science' paper as vantage point and ground for reflection. International Journal of Geographical Information Science, 26 (12), 2291-2300.

DumBILL, E. (2013), The future of programming. Unraveling what programming will need for the next 10 years. http://radar.oreilly.com/2013/01/the-future-of-programming.html.

Elwood, S. \& LESZCZYNSKI, A. (2011), Privacy, reconsidered: New representations, data practices, and the geoweb. GeoJournal, 42 (1), 6-15.

X-devonthink-item://1E735F18-F24E-4D7E-B9AB-BB35A2E2ACDC.

FISHER, T. (2012), Place-Based Knowledge in the Digital Age. http://www.esri.com/news/arcnews/fall12articles/place-based-knowledge-in-the-digitalage.html.

GIBSON, W. (2012), Distrust that Particular Flavor. Putnam Adult. http://books.google.com/books?hl=en\&lr=\&id=XqSBnRdelLwC\&oi=fnd\&pg=PT1\&dq $=$ distrust + that + particular + flavor\&ots $=H S 89 v 9 \mathrm{mPsg} \& s i g=$ GmZE1ZhztlplbZAsoFNcriG 1QKs. 
GoodchiLd, M. F. (2007), Citizens as sensors: the world of volunteered geography. Geojournal, 69 (2), 11-21.

Gould, M., Craglia, M., Goodchild, M. F., Annoni, A., Camara, G., Kuhn, W., Liang, S. (2008), Next-generation digital earth: A position paper from the vespucci initiative for the advancement of geographic information science. International Journal of Spatial Data Infraestructures Research (17250463), 3. http://repositori.uji.es/xmlui/bitstream/handle/10234/18493/30872.pdf?1.

GRYL, I. \& JEKEL, T. (2012), Re-centring Geoinformation in Secondary Education: Toward a Spatial Citizenship Approach. Cartographica: The International Journal for Geographic Information and Geovisualization, 47 (1), 18-28.

http://utpjournals.metapress.com/index/Q0V1415335554175.pdf.

Haklay, M., Singleton, A. \& PARKer, C. (2008), Web mapping 2.0: The neogeography of the GeoWeb. Geography Compass, 2 (6), 2011-2039.

http://week9neogeog.pbworks.com/w/page/f/Web+Mapping+2.0+The+Neogeography+ of + the + GeoWeb.pdf.

HARVEY, F. (in press), We know where you are. And we're more and more sure what that means. In Pervasive Information Communication Technology (p. tbd). Berlin, Springer.

Harvey, F., Kne, L. \& MAnson, S. (2013), U-Spatial: A Consortium for the Spatial University.

http://www.esri.com/esri-news/arcnews/winter1213articles/u-spatial-a-consortium-forthe-spatial-university.

Harvey, Francis, Iwaniak, A., Coetzee, S. \& Cooper, A. K. (2012), SDI Past, Present and Future: A Review and Status Assessment. In: RAJABIFARD, A. \& ColEMAN, D. (Eds.), Spatial Enabling Government, Industry and Citizens. Needham, MA, GSDI Association Press.

Hendriks, P., Dessers, E. \& VAn Hootegem, G. (2012), Reconsidering the definition of a Spatial Data Infrastructure. International Journal of Geographical Information Science, 26 (8), 1479-1494.

HowARD, A. (2013), On the power and perils of "preemptive government". Stephen Goldsmith on the potential of urban predictive data analytics in municipal government. http://strata.oreilly.com/2013/02/preemptive-government-predictive-data.html.

Kurgan, L. (2013), Close Up at a Distance: Mapping, Technology, and Politics. Zone Books.

http://books.google.com/books?hl=en\&lr=\&id=VKFL4L0dGioC\&oi=fnd\&pg=PA5\&dq $=$ kurgan + close + up\&ots $=$ GBvQgYXDu5\&sig=Sscp3KegDuUL3KLrT89pn yiN2U.

Maceachren, A. M., Cai, G., Sharma, R., Rauschert, I., Brewer, I., Bolelli, L., WANG, H. (2005), Enabling collaborative geoinformation access and decision-making through a natural, multimodal interface. International Journal of Geographical Information Science, 19 (3), 293-317.

MacEachren, A. M. (1995), How Maps Work. Representation, Visualization, Design. New York, The Guildford Press.

Mogel, L. \& Bhagat, A. (Eds) (2007), An Atlas of Radical Cartography. Journal of Aesthetics and Protest Press.

Norman, D. A. (1993), Things That Make Us Smart: Defending Human Attributes in the Age of the Machine. Addison-Wesley Publishing Company.

Roche, S., Nabian, N., Kloeckl, K. \& Ratti, C. (2012), Are 'Smart Cities' Smart Enough. http://www.gsdi.org/gsdiconf/gsdi13/papers/182.pdf. 
Solis, B. (2012), The Rise of Digital Influence. Altimeter Group.

http://www.webcarecompany.nl/wp-content/uploads/The_rise_of_digital_influence.pdf.

Solnit, R. (2010), Infinite City: A San Francisco Atlas. University of California Press.

STAR, S. L. (1999), The ethnography of infrastructure. American Behavioral Scientist, 43 (3), 377-391.

STAR, S. L. \& RUHLEDER, K. (1996), Steps towards and ecology of infrastructure: Design and access for large-scale collaborative systems. Information Systems Research, 7, 111138.

SuI, D. (2012), Beyond mathematics and the deflationary turn: fundamental concepts in GIScience - To whom and for what ends? In: HARVEY, F. (Ed.), Are there fundamental principles in Geographic Information Science? Seattle, CreateSpace/Amazon Kindle.

TURNER, A. (2006), Introduction to neogeography. Sebastopol, CA: O'Reilly Media. http://pcmlp.socleg.ox.ac.uk/sites/pcmlp.socleg.ox.ac.uk/files/Introduction_to_Neogeog raphy.pdf.

Walcott-Bryan, A., Kaess, M., Johannsson, H. \& LeOnard, J. J. (2012), Dynamic Pose Graph SLAM: Long-term Mapping in Low Dynamic Environments. Proceedings from the International Conference on Intelligent Robots and Systems (IROS), Vilamoura, Portugal. 1871-1878.

WING, J. M. (2006), Computational thinking. Communications of the ACM, 49 (3), 33-35. http://www-cgi.cs.cmu.edu/afs/cs/usr/wing/www/CT_at_CMU.pdf.

WORLD BANK (2012), Mobile Phone Access Reaches Three Quarters of Planet's Population. http://www.worldbank.org/en/news/press-release/2012/07/17/mobile-phone-accessreaches-three-quarters-planets-population.

Wright, D. (2012), Theory and application in a post-GISystems world. International Journal of Geographical Information Science, 26 (12), 2197-2209. 